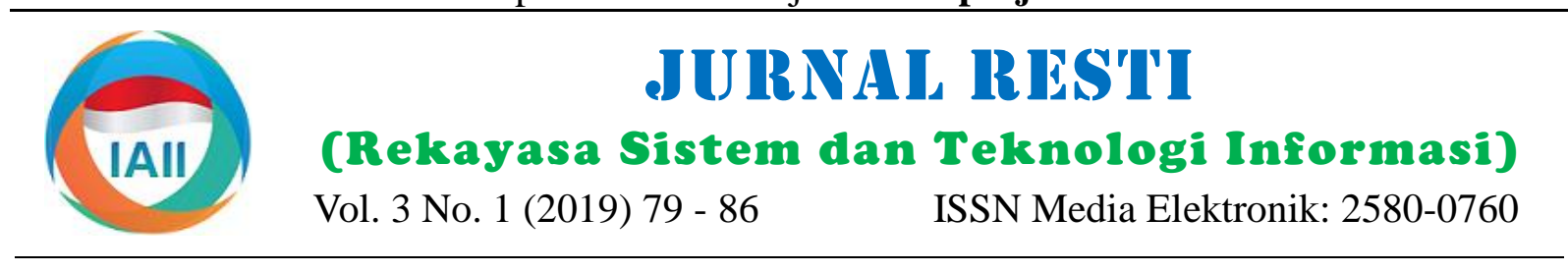

\title{
Sistem Tutorial Berbasis Kecerdasan Buatan Pada Proses Pengambilan Keputusan Perawatan dan Perbaikan Gitar
}

\author{
Agusta Rakhmat Taufani ${ }^{1}$, Harits Ar Rosyid ${ }^{2}$ \\ ${ }^{1,2}$ Teknik Elektro, Fakultas Teknik, Universitas Negeri Malang \\ ${ }^{1}$ agusta.rakhmat.ft@um.ac.id, ${ }^{2}$ harits.ar.ft@um.ac.id
}

\begin{abstract}
Guitar is a popular musical instrument in the world and is a metronome for every use in various music events and its correlation. As a metronome, the guitar must be well standardized on the quality of each part so that sound that comes in line with the user's expectations in this case is the guitarist. Damage to the guitar is something normal because of its intense use so it needs proper handling in the repair process. The easiest thing is to bring a broken guitar to the experts, but when there are not many guitar service experts or a long enough distance to reach it, then guitar repairs need to be done immediately. Therefore, it is necessary to develop a system that can act as a tutor in the maintenance and repair of guitars by utilizing artificial intelligence embedded in the system. With the help of artificial intelligence, it is expected that the system can assist in the decision making of guitar technicians in the process of making guitar repair decisions based on the symptoms that occur. Decision making used uses the certainty factor method based on certainty factors. After going through the equivalence partitioning testing process, in general this system produces a total percentage of $100 \%$ on the success of the item test by experts in the testing process of the 25 items tested. Thus the application meets the requirements for making the program, which is readable and valid.
\end{abstract}

Keywords: tutoring system, guitar, artificial intelligence

\begin{abstract}
Abstrak
Gitar merupakan alat musik yang populer di dunia dan menjadi metronom pada setiap penggunaannya dalam berbagai event musik dan korelasinya. Sebagai metronom, gitar pasti harus terstandar dengan baik pada kualitas tiap bagiannya agar suara yang keluar sesuai dengan harapan user dalam hal ini adalah gitaris. Kerusakan pada gitar merupakan sesuatu yang normal karena penggunaannya yang intens sehingga perlu penanganan yang benar dalam proses perbaikannya. Hal yang paling mudah adalah dengan membawa gitar yang rusak pada ahlinya, tetapi ketika jumlah ahli servis gitar yang tidak banyak atau jarak yang cukup jauh untuk menjangkaunya, maka perbaikan gitar perlu untuk segera dilakukan. Oleh karena itu, perlu dikembangkan suatu sistem yang bisa berperan sebagai tutor dalam perawatan dan perbaikan gitar dengan memanfaatkan kecerdasan buatan yang ditanamkan dalam sistem. Dengan bantuan kecerdasan buatan diharapkan sistem dapat membantu dalam pengambilan keputusan teknisi gitar dalam proses pengambilan keputusan perbaikan gitar berdasarkan gejala yang terjadi. Pengambilan keputusan yang digunakan menggunakan metode certainty factor yang berbasis pada faktor kepastian. Setelah melalui proses pengujian equivalence partitioning, secara garis besar sistem ini menghasilkan total prosentase $100 \%$ pada kesuksesan uji item oleh pakar pada proses testing dari 25 uji item yang dilakukan. Dengan demikian maka aplikasi memenuhi syarat pembuatan program yaitu readable dan valid.
\end{abstract}

Kata kunci: sistem tutorial, gitar, kecerdasan buatan.

(c) 2019 Jurnal RESTI

\section{Pendahuluan}

Gitar merupakan alat musik yang hampir selalu ada pada berbagai genre musik. Kata gitar (guitar) diambil dari sebutan untuk alat musik kuno wilayah Persia pada tahun 1500 SM. Alat musik ini sebelumnya lazim disebut citar atau sehtar. Alat ini menjadi metronome dalam sebuah pertunjukan konser khususnya pada format grup band. Banyak grup band yang dikenal karena kepiawaian gitarisnya dalam memainkan alat musik ini. Jenis dan bentuk gitar sangat bervariasi

Diterima Redaksi : 29-03-2019 | Selesai Revisi : 11-04-2019| Diterbitkan Online : 30-04-2019 
mengikuti kebudayaan serta perkembangan zaman. Sistem tutorial berbasis kecerdasan buatan atau yang Walaupun demikian, inti dari alat musik ini merupakan biasa disebut Intelligent Tutoring System (ITS) alat musik petik yang bahan dasarnya terbuat dari kayu bertujuan untuk mewakili pengetahuan dan membawa dengan beberapa bagian dari logam atau metal dan pada interaksi dengan peserta didik. Komponenterdapat 6 tali senar untuk dimainkan. Bagian atas dan komponen yang membentuk ITS ditunjukkan pada bawah dari badan gitar berbentuk angka 8. Senar terikat gambar 3 [9]. pada pegs atau pemutar senar yang ditarik sepanjang badan gitar. Pegs digunakan untuk proses tuning. Bunyi gitar mengandung unsur romantisme sehingga mayoritas lagu yang dimainkan dengan peralatan ini bergenre romantis dengan variasi genre yang lain. Selain gitar tradisional secara dasar, terdapat jenis gitar yang lain di antaranya: Gitar Hawaiian berbasis sistem slide, gitar berbasis dawai nylon (gitar klasik dan gitar folk), dan gitar berbasis dawai logam (gitar listrik). Contoh salah satu jenis gitar dapat dilihat pada gambar $1[2]$.

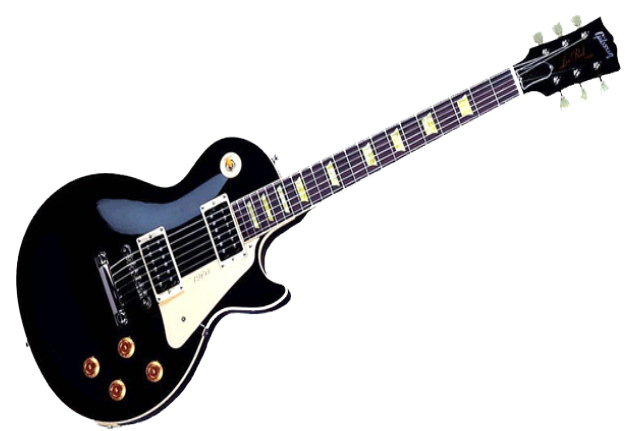

Gambar 1. Gitar Listrik

Sebagai metronom dalam sebuah pertunjukan konser solo atau band, gitar pasti harus terstandar dengan baik pada kualitas tiap bagiannya agar suara yang keluar sesuai dengan harapan user dalam hal ini adalah gitaris. Kerusakan pada gitar merupakan sesuatu yang normal karena penggunaannya yang intens sehingga perlu penanganan yang benar dalam proses perbaikannya. Hal yang paling mudah adalah dengan membawa gitar yang rusak pada ahlinya, tetapi ketika jumlah ahli servis gitar yang tidak banyak atau jarak yang cukup jauh untuk menjangkaunya, maka perbaikan gitar perlu untuk segera dilakukan.

Kecerdasan Buatan atau Artificial Intelligence (AI) merupakan salah satu disiplin ilmu pada bidang komputer yang selalu mengalami pembaruan. Bidang ini mempunyai tujuan tidak hanya berbasis pada pemahaman, tetapi juga pembangunan entitas cerdas. AI meliputi banyak sub-bidang, mulai dari bidang umum sampai untuk beberapa tugas spesifik. Definisi AI dapat diklasifikasian menjadi dua dimensi utama yang membahas proses atau penalaran berpikir (reasoning) dan perilaku atau tindakan (behavior) [8]. Selanjutnya definisi AI dapat dijabarkan lagi berdasarkan kinerja (performance) dan rasionalitasnya. Keempat sudut pandang tersebut membentuk matriks definisi AI, seperti yang terdapat pada gambar 2 .

\begin{tabular}{|l|l|}
\hline $\begin{array}{l}\text { Sistem yang berpikir } \\
\text { seperti manusia } \\
\text { Thinking humanly }\end{array}$ & $\begin{array}{l}\text { Sistem yang berpikir } \\
\text { secara rasional } \\
\text { Thinking rationally }\end{array}$ \\
\hline $\begin{array}{l}\text { Sistem yang bertindak } \\
\text { seperti manusia } \\
\text { Acting humanly }\end{array}$ & $\begin{array}{l}\text { Sistem yang bertindak } \\
\text { secara rasional } \\
\text { Acting rationally }\end{array}$ \\
\hline
\end{tabular}

Gambar 2. Matriks Definisi Kecerdasan Buatan

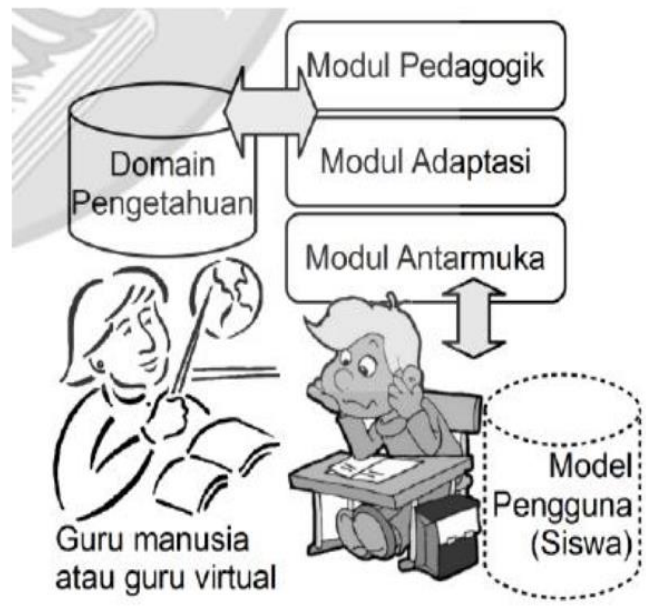

Gambar 3. Komponen Sistem Tutorial Berintelegensia

Perbaikan merupakan usaha untuk mengembalikan kondisi dan fungsi dari suatu benda atau alat yang rusak akibat pemakaian alat tersebut pada kondisi semula. Proses perbaikan tidak menuntut kepresisian kondisi awal, tetapi bertujuan alat pada kondisi normal atau bisa digunakan. Perbaikan memungkinkan pergantian spare part. Beberapa produk yang ada di pasaran kadangkala tidak menyediakan spare part untuk penggantian saat proses perbaikan, harganya hampir mendekati harga baru satu unit produk tersebut jika stok tersedia. Hal ini yang mengharuskan user untuk membeli baru produk yang sama [10].

Untuk menjaga standarisasi gitar, bila ditemukan ada gejala kerusakan yang timbul harus bisa tertangani proses perbaikannya secara cepat dan tepat. Oleh karena itu, perlu dikembangkan suatu sistem yang bisa berperan sebagai tutor dalam perawatan dan perbaikan gitar dengan memanfaatkan kecerdasan buatan yang ditanamkan dalam sistem. Dengan bantuan kecerdasan buatan diharapkan sistem dapat membantu dalam

Jurnal RESTI (Rekayasa Sistem dan Teknologi Informasi) Vol. 3 No. 1 (2019) 79 - 86 
pengambilan keputusan teknisi gitar atau user berdasarkan gejala yang terjadi. Pengambilan keputusan yang digunakan menggunakan metode certainty factor yang berbasis pada faktor kepastian.

\section{Metode Penelitian}

Penelitian ini menggunakan metode kualitatif dan kuantitatif. Metode kualitatif meliputi tahapan penemuan masalah kemudian mengkaji studi literatur yang berkaitan dengan cara untuk menyelesaikan masalah yang terjadi. Sementara pada metode kuantitatif yaitu tahapan mengolah data yang telah didapatkan dari tahapan sebelumnya. Perancangan dan pembangunan sistem menggunakan metode software development life cycle dengan mengadopsi model waterfall. Tahapan utama dari model waterfall mencerminkan aktifitas pengembangan dasar secara langsung [7]. Tahapan pada model waterfall ditunjukkan pada gambar 4.

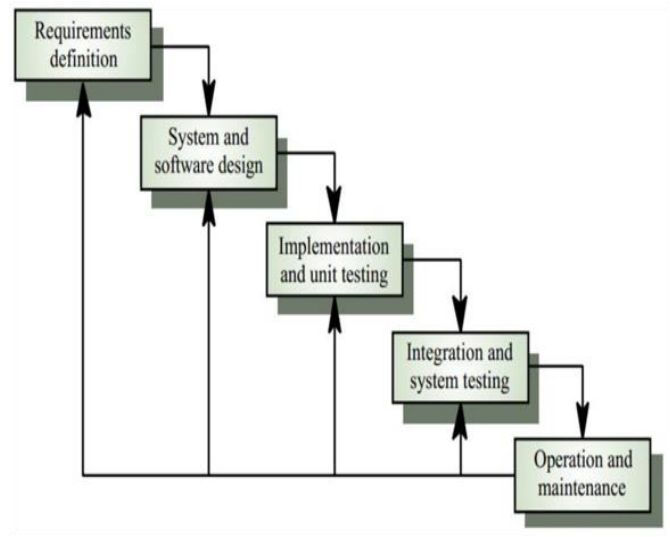

. Gambar 4. Tahapan Model Waterfall

Requirements definition: Pada proses ini dilakukan pencarian kebutuhan sistem atau software. Dalam membangun sistem ini telah dirancang model use case diagram untuk menginterpretasikan fungsi interface dari sisi pengguna (user). Desain use case diagram sistem ditunjukkan pada gambar 5 .

Use Case Diagram pada gambar 5 menjelaskan bahwa actor user memiliki empat aktivitas yang dapat dilakukan yaitu melakukan diagnosa kerusakan, melihat informasi data gejala, mengakses menu login dan mengakses menu diagnosa.

Pada proses system and software design, dilakukan perancangan sistem di mana desain yang dibuat harus dapat mengimplementasikan kebutuhan yang telah disebutkan pada tahap sebelumnya. Perancangan pada sistem ini dibuat dengan menggunakan metode UML (Unified Modelling Language). Desain perancangan dalam penelitian ini menggunakan empat model perancangan, yaitu: flowchart, class diagram, sequence diagram dan activity diagram.

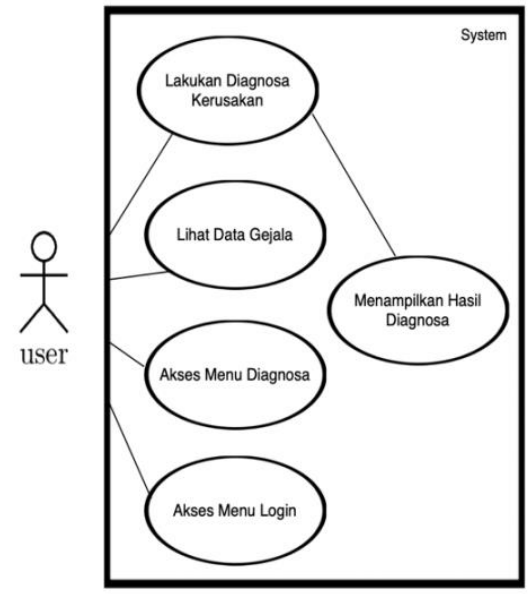

Gambar 5. Model Use Case Diagram

Pada sistem ini terdapat satu actor yang terlibat yaitu pengguna (user). Secara garis besar, proses-proses yang dilakukan pengguna dan sistem dapat digambarkan dalam bentuk flowchart. Flowchart menunjukkan gambaran bisnis proses yang merupakan kumpulan proses yang berisi kumpulan aktivitas terstruktur dan saling berelasi satu sama lain untuk menghasilkan keluaran diagnosa kerusakan gitar. Flowchart antara pengguna dan sistem ditunjukkan pada gambar 6 .

Class diagram merupakan diagram yang digunakan untuk menampilkan beberapa kelas serta beberapa paket yang ada pada sistem aplikasi. Model class diagram sistem ditunjukkan pada gambar 7.

Sequence diagram berguna untuk melihat spesifikasi dari sebuah pilihan button sehingga user dapat memilih button tersebut dan akan ditampilkan sub-menu dari masing-masing button tersebut. Pada sistem ini proses sequence diagram ditunjukkan pada gambar 8 .

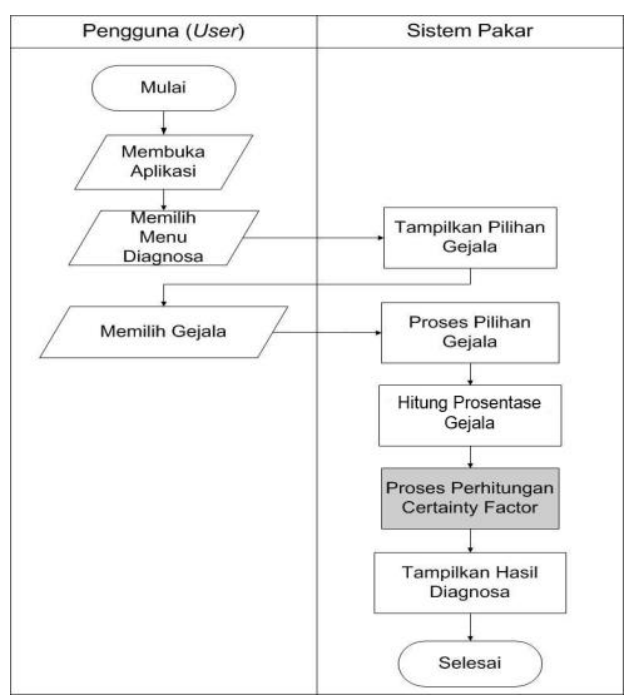

Gambar 6 Diagram Alir Sistem

Jurnal RESTI (Rekayasa Sistem dan Teknologi Informasi) Vol. 3 No. 1 (2019) 79 - 86 
Activity diagram merupakan diagram yang black box testing dan perbaikan kesalahan yang terjadi, menggambarkan workflow (aliran kerja) atau aktivitas maka aplikasi sistem diujicobakan kepada pengguna. dari sebuah sistem atau proses bisnis [3]. Pada sistem ini proses activity diagram ditunjukkan pada gambar 9 .

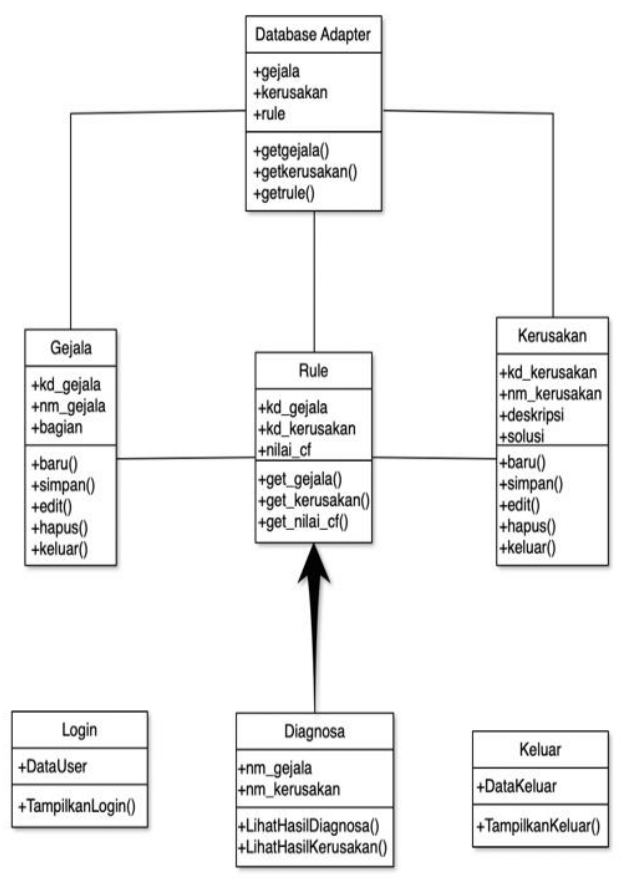

Gambar 7. Model Class Diagram

Antarmuka sistem dibuat sebagai penghubung antara sistem dengan pengguna (user). Pada rancangan antarmuka sistem ini terdapat beberapa halaman yang dapat diakses oleh pengguna.

Setelah parameter didapatkan, maka dilakukan proses coding untuk mengimplementasikan desain pada prototype. Setelah proses coding selesai, dilakukan proses pengujian dengan menggunakan metode white box dan black box. White box testing merupakan pengujian pada modul pengkodean program untuk menjamin kode program bebas dari kesalahan sintaks maupun logika [6].

Pengujian black box merupakan pengujian pada aspek fundamental sistem tanpa memperhatikan struktur logika internal perangkat lunak yang terfokus pada pengujian fungsionalitas sistem agar keluaran sesuai dengan apa yang diharapkan user [1]. Pada tahap ini, sebelum proses uji coba aplikasi sistem kepada user, terlebih dahulu dilakukan ujicoba black box. Jadi, dianalogikan seperti kita melihat suatu kotak hitam, kita hanya bisa melihat penampilan luarnya saja, tanpa tahu ada apa di balik bungkus hitamnya. Kategori error yang akan diketahui melalui black box testing yaitu: fungsi yang hilang atau tidak benar, error dari antarmuka, error dari struktur data atau akses eksternal database, error dari kinerja atau tingkah laku, serta error dari inisialisasi dan terminasi. Setelah proses

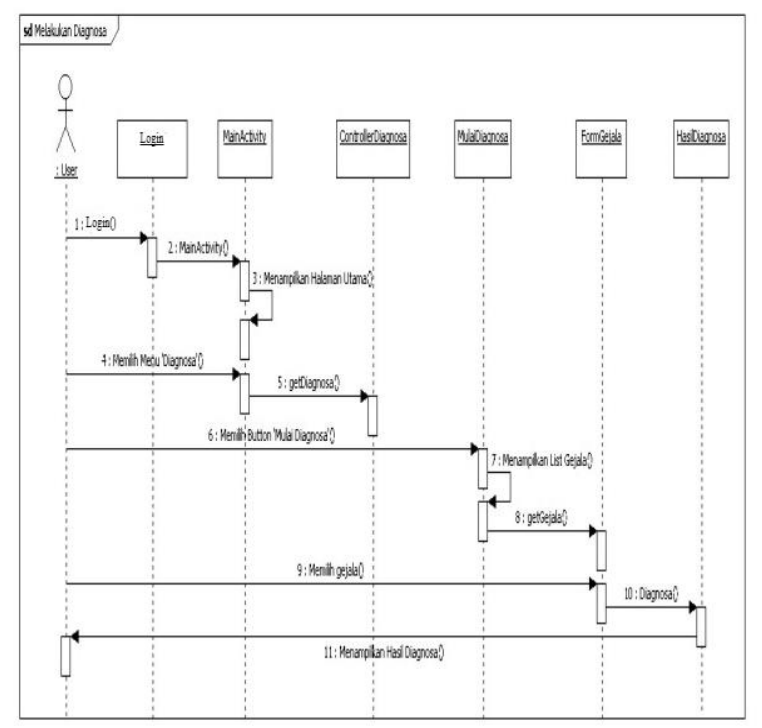

Gambar 8. Sequence Diagram Proses Diagnosa

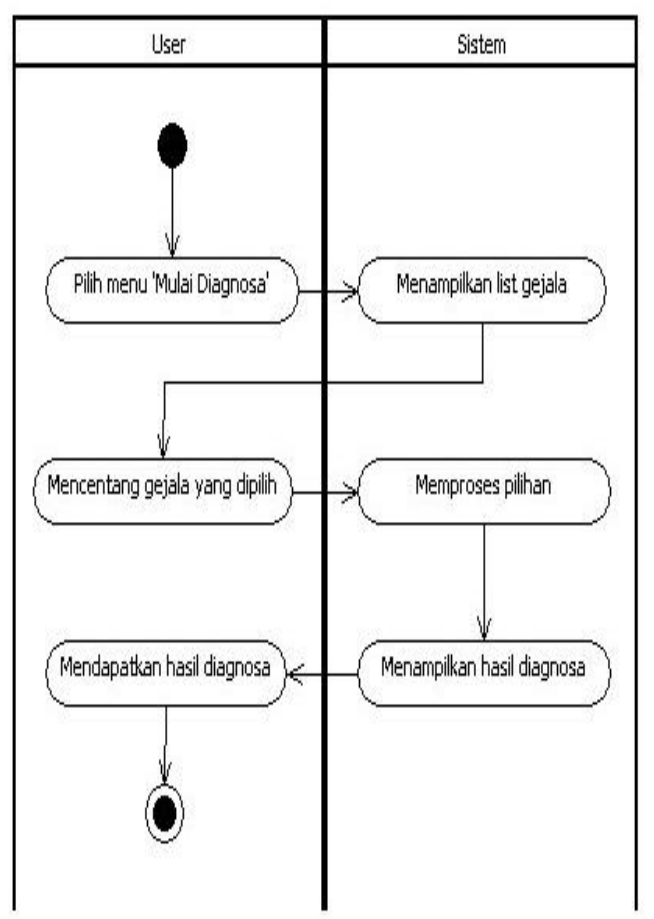

Gambar 9. Activity Diagram Proses Diagnosa

Deskripsi urutan penelitian yang dilakukan meliputi studi literatur, teknik pengumpulan data, perancangan, dan implementasi sistem. Tahapan yang digunakan dalam penelitian digambarkan dalam bentuk diagram alir ditunjukkan pada gambar 10 .

Studi literatur merupakan tahap awal penelitian. Tahap ini untuk mendapat gambaran umum maupun khusus mengenai objek maupun teori pendukung. Studi 
literatur yang digunakan adalah: buku pedoman, buku 6. Perhitungan nilai CF dari gejala kerusakan user.

online, dan jurnal online yang relevan.

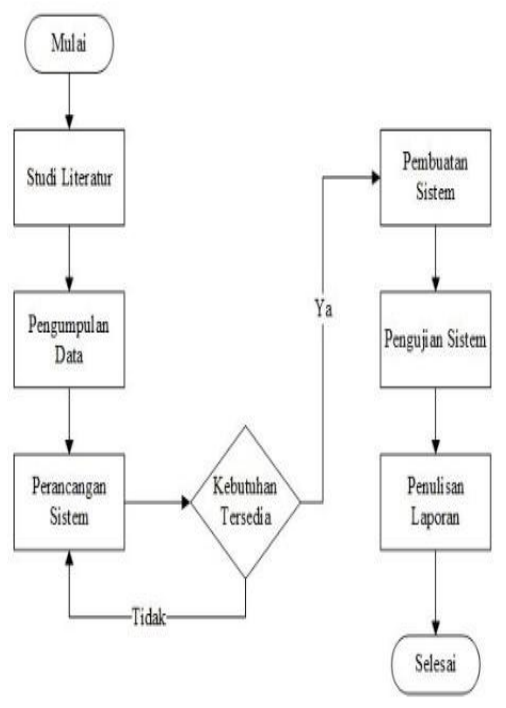

Gambar 10. Diagram Alir Sistem

Pengumpulan data bertujuan untuk memperoleh informasi yang dibutuhkan meliputi: data primer yang merupakan sumber data yang didapatkan langsung dari sumber informasi. Contoh kebutuhan data primer adalah data kerusakan, data gejala, data gabungan dan data nilai cf yang diperoleh dari pakar sebagai data penentuan nilai certainty factor pada penerapan sistem tutorial berbasis kecerdasan buatan pada proses pengambilan keputusan perawatan dan perbaikan gitar. Data sekunder yang merupakan data pendukung didapatkan dari sumber lain selain tempat penelitian namun masih relevan dengan objek penelitian.

Tahap awal perancangan dan pengembangan sistem adalah menentukan kebutuhan sistem diagnosis dan jenis kerusakan gitar yang akan dibangun. Pada tahap ini, dilakukan studi literatur yang mempelajari tentang sistem pendukung pakar dan metode certainty factor untuk sistem tutorial melalui berbagia media, antara lain melalui internet, jurnal, dan buku yang berhubungan dengan sistem serta kompleksitas data yang dibutuhkan untuk membangun sistem tersebut.

Langkah-langkah perhitungan dalam metode certainty factor untuk membangun sistem tutorial berbasis kecerdasan buatan perawatan dan perbaikan gitar adalah sebagai berikut:

1. Penentuan data kerusakan.

2. Penentuan data gejala.

7. Hasil diagnosis kerusakan.

8. Hasil diagnosis sistem berupa prosentase kerusakan. Prosentase kerusakan yang digunakan untuk hasil diagnosis merupakan prosentase terbesar. Prosentase kerusakan didapatkan dari perhitungan nilai certainty factor berdasarkan gejala yang dipilih oleh user. Perhitungan nilai certainty factor adalah sebagai berikut.

1. Menghitung Nilai $\mathrm{CF}$

$C F[H, E]=M B[H, E]-M D[H, E]$

Keterangan :

$\mathrm{CF}(\mathrm{H}, \mathrm{E})$ : certainty factor dari hipotesis $\mathrm{H}$ yang dipengaruhi oleh gejala (evidence) E. Besarnya CF antara -1 sampai 1. Nilai -1 menunjukkan ketidakpercayaan mutlak, sedangkan nilai 1 menunjukkan kepercayaan mutlak.

$\mathrm{MB}(\mathrm{H}, \mathrm{E})$ : ukuran kepercayaan (measure of increased belief) terhadap hipotesis $\mathrm{H}$ yang dipengaruhi oleh gejala E.

$\mathrm{MD}(\mathrm{H}, \mathrm{E})$ : ukuran ketidakpercayaan (measure of increased disbelief) terhadap hipotesis $\mathrm{H}$ yang dipengaruhi oleh gejala E.

2. Menghitung Nilai CFcombine

$\mathrm{CF}$ combineCF[H,E $] 1,2=\mathrm{CF}[\mathrm{H}, \mathrm{E}] 1+\mathrm{CF}[\mathrm{H}, \mathrm{E}] 2$

* $[1-\mathrm{CF}[\mathrm{H}, \mathrm{E}] 1]$

Tahapan desain sistem menggunakan Unified Modeling Language (UML) yang mendukung konsep pemodelan programming berbasis Object Oriented Programming (OOP) seperti yang akan diterapkan pada tahap penulisan kode program. Pada tahap ini akan diperoleh dokumentasi pemodelan, antara lain: Business Process, Use Case Diagram, Use Case Scenario, Sequence Diagram, Activity Diagram, Class Diagram, dan Entity Relationship Diagram (ERD).

Tahapan implementasi merupakan proses konversi desain sistem ke dalam kode program. Penulisan kode program (coding) menggunakan bahasa pemograman Visual Basic (Vb) dengan supervisi Sublime Text. Sementara Microsoft (MS) Access digunakan pada manajemen basis data.

Pasca proses implementasi adalah tahap testing atau pengujian sistem. Metode ini menggunakan white box testing dan black box testing.

Sistem tutorial berbasis kecerdasan buatan pada proses

3. Penentuan data gabungan; data gabungan yang pengambilan keputusan perawatan dan perbaikan gitar dimaksud merupakan data gabungan antara data digambarkan pada suatu grand design dalam kebutuhan gejala dengan data alternatif kerusakan.

fungsional dan non-fungsional, use case diagram, dan

4. Penentuan nilai MB dan MD dilanjutkan dengan Entity Relationship Diagram (ERD). penentuan nilai $\mathrm{CF}$.

5. Pemilihan data gejala kerusakan oleh user. 
Kebutuhan fungsional sistem merupakan kebutuhan sequence diagram manajemen data gabungan, sequence yang harus dimiliki sistem. Kebutuhan fungsional pada diagram manajemen ubah data user, sequence diagram sistem ini terdiri atas: tambah dan hapus data gabungan, dan sequence

1. Sistem mampu mengelola data kerusakan beserta diagram konsultasi. alternatifnya.

2. Sistem mampu mengelola data gejala.

3. Sistem mampu mengelola data gabungan gejala dengan kerusakan atau alternatif.

4. Sistem mampu mengupdate nilai certainty factor (CF).

Class diagram pada sistem ini terdiri dari tiga package utama dan tiga class parents meliputi package view, package controller, package model, class CI loader, class CI_controller, dan class CI model.

5. Sistem dibangun dengan mengimplementasikan metode certainty factor $(\mathrm{CF})$.

6. Sistem dapat membantu user melakukan proses konsultasi terhadap gejala dan alternatif kerusakan pada gitar.

7. Sistem mampu menampilkan data gejala dan alternatif kerusakan yang ada untuk user.

ERD merupakan model struktur data dan hubungan antar data. Objek dalam ERD digambarkan dalam sebuah entitas yang memiliki berbagai atribut yang berelasi dengan entitas lainnya. Proses pembangungan sistem ini menggunakan 8 entitas dengan relasi one to many [4].

Kebutuhan non fungsional merupakan kebutuhan tambahan untuk melengkapi sistem. Kebutuhan non fungsional sistem meliputi:

1. Tampilan user friendly untuk memudahkan user.

2. Sistem menggunakan username dan password sebagai otentifikasi user saat mengakses sistem.

Business process system merupakan gambaran rangkaian kegiatan mengenai kebutuhan dan hasil dari sistem berupa gambar masukan (input), keluaran (output), dan tujuan (goal) yang terstruktur.

Use case diagram menggambarkan sebuah interaksi antar satu atau lebih aktor dengan fitur-fitur sistem dan menunjukkan fungsionalitas yang diharapkan dari sebuah sistem untuk user. Use case ini dibagi berdasarkan kemampuan (fitur) sistem [5].

Skenario digunakan untuk menjelaskan detail dari use case diagram. Skenario meliputi nama use case, aktor, Pre Condition, Post Condition, skenario normal, dan skenario alternatif. Terdapat 7 skenario untuk membangun sistem tutorial berbasis kecerdasan buatan pada proses pengambilan keputusan perawatan dan perbaikan gitar. Skenario meliputi skenario mengubah data pakar, skenario manajemen data alternatif kerusakan, skenario manajemen data gejala kerusakan, skenario tambah dan hapus data gabungan, skenario manajemen data gabungan, skenario konsultasi dan skenario lihat daftar gejala kerusakan.

Activity diagram meliputi activity diagram manajemen data alternatif kerusakan, activity diagram manajemen data gejala kerusakan, activity diagram manajemen data gabungan, activity diagram manajemen ubah data user, activity diagram tambah dan hapus data gabungan dan activity diagram konsultasi.

\section{Hasil dan Pembahasan}

Hasil rancang bangun sistem dalam penelitian ini menghasilkan sistem tutorial berbasis kecerdasan buatan pada proses pengambilan keputusan perawatan dan perbaikan gitar. Tampilan awal sistem ditunjukkan pada gambar 11 .

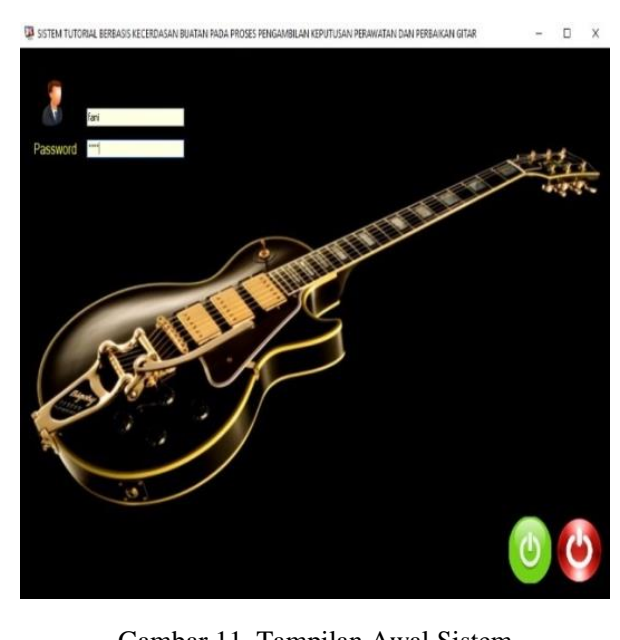

Setelah user melakukan otentifikasi lewat form login maka user akan dialihkan pada menu utama. Fitur pada menu utama yaitu menu master data, diagnosa, dan keluar dari sistem. Menu master data memuat gejala kerusakan, alternatif kerusakan, dan basis aturan. Form gejala kerusakan memuat gejala kerusakan yang timbul pada gitar. Penentuan nilai CF oleh pakar dimuat pada form alternatif kerusakan. Menu basis aturan merupakan menu gabungan (kombinasi) antara alternatif kerusakan dengan gejala kerusakan harddisk dengan penentuan MB dan MD. Form master data ditunjukkan pada gambar 12 .

Menu diagnosa berfungsi untuk melakukan perhitungan Sequence diagram pada sistem meliputi sequence terhadap kombinasi data gejala kerusakan yang dipilih diagram manajemen data alternatif kerusakan, oleh user, secara otomatis sistem akan melakukan sequence diagram manajemen data gejala kerusakan, perhitungan certainty factor untuk mendapatkan hasil

Jurnal RESTI (Rekayasa Sistem dan Teknologi Informasi) Vol. 3 No. 1 (2019) 79 - 86 
prosentase tipe kerusakan gitar beserta solusinya. Hasil Tabel 2 menunjukkan pengujian fungsional yang penelusuran diagnosa ditunjukkan pada gambar 13. dilakukan oleh pakar untuk memastikan bahwa semua

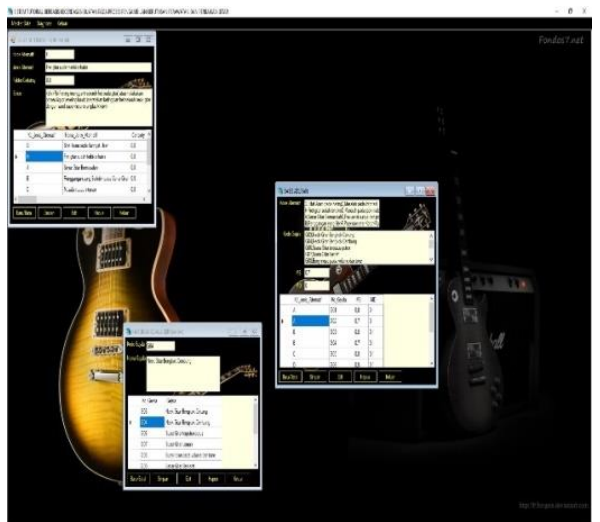

Gambar 12. Tampilan Menu Utama

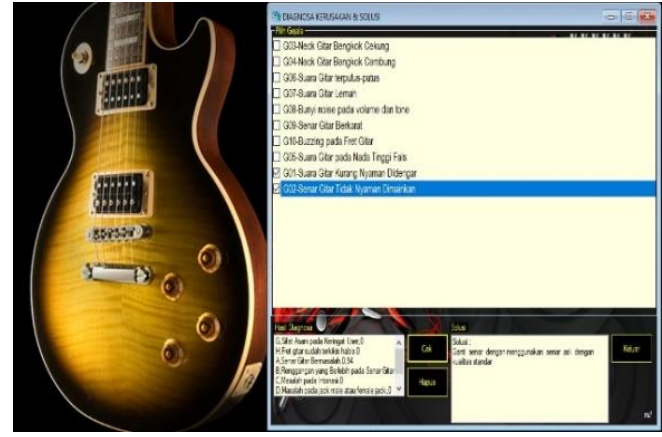

Gambar 13. Tampilan Menu Diagnosa

Perhitungan nilai certainty factor diaplikasikan dari potongan source code berikut ini:

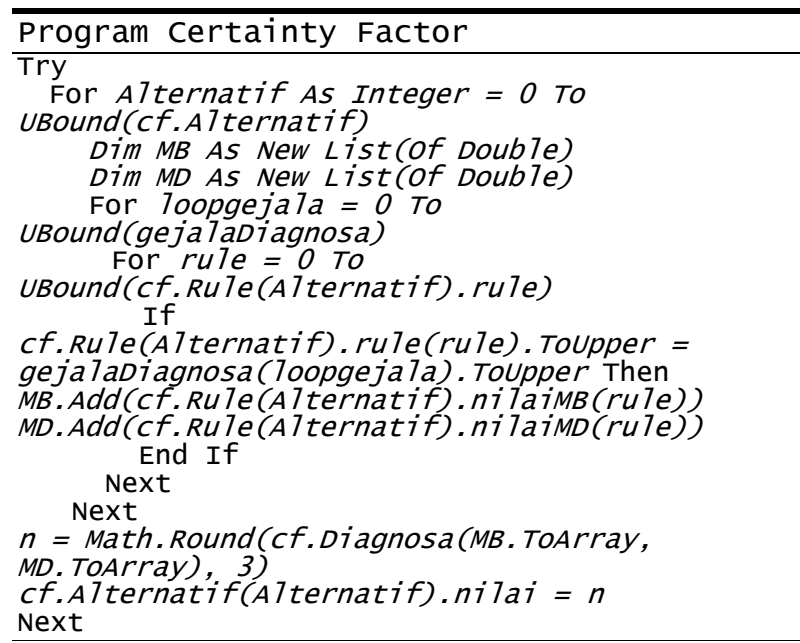
Tabel 1 menunjukkan pengujian fungsional yang pada kesuksesan uji item oleh pakar pada proses dilakukan terhadap perangkat lunak untuk memastikan testing. Dengan demikian maka aplikasi memenuhi bahwa semua kebutuhan telah terpenuhi pada sistem syarat pembuatan program yaitu readable dan valid. operasi tertentu dalam hal ini Windows XP pada minimum requirements sampai Windows 10.

\section{Kesimpulan}

Sistem tutorial berbasis kecerdasan buatan pada proses pengambilan keputusan perawatan dan perbaikan gitar

Jurnal RESTI (Rekayasa Sistem dan Teknologi Informasi) Vol. 3 No. 1 (2019) 79 - 86 
dapat membantu dalam proses diagnosa masalah yang Daftar Rujukan terjadi pada gitar berdasarkan pengujian baik itu melalui black box maupun white box dengan indikator similaritas dengan perencanaan prototype. Proses pengujian sistem merepresentasikan prosentase hasil diagnosa dengan menggunakan proses perhitungan Certainty Factor (CF). Nilai CF dipengaruhi dari nilai yang ditentukan oleh pakar. Metode ini cocok dipakai untuk mengukur kepastian atau ketidakpastian dalam mendiagnosa kerusakan gitar. Akurasi Data dapat terkondisi dengan baik mengingat proses perhitungan menggunakan metode ini dalam sekali hitung hanya dapat mengolah 2 data. Berdasarkan perhitungan pada proses testing maka sistem ini secara garis besar menghasilkan total prosentase $100 \%$ pada kesuksesan uji item oleh pakar. Dengan demikian maka aplikasi memenuhi syarat pembuatan program yaitu readable dan valid, dengan indikator semua fitur pada sistem dapat dijalankan sesuai konsep perancangan. Pengembangan penelitian selanjutnya dapat dilakukan melalui migrasi sistem dari berbasis desktop ke mobile berbasis iOS atau android, mengingat kecenderungan user yang sering memakai gadget mobile-nya yang dapat diakses setiap saat daripada berhadapan dengan komputer.

[1] Alfaris H.B.I., Anam C., dan Masy'an A., 2013. Implementasi Black Box Testing Pada Sistem Informasi Pendaftaran Santri Berbasis Web Dengan Menggunakan PHP Dan MySQ1. SAINTEKBU: Jurnal Sains dan Teknologi, 6(1), pp. 23-38.

[2] Devin, 2014. Devin's Guitar Collection. [Online]. Tersedia di: https://codehs.com/editor/html/1262139/755546/index.html/ [Accessed 25 Desember 2018]

[3] Isa I.G.T., dan Hartawan G.P., 2017. Perancangan Aplikasi Koperasi Simpan Pinjam Berbasis Web (Studi Kasus Koperasi Mitra Setia). Jurnal Ilmiah Ilmu Ekonomi, 5(10), pp. 139-151.

[4] Kostaman N., dan Sumaryana Y., 2018. Aplikasi Pemesanan Tiket Oto Bus Budiman Berbasis Online. JUMANTAKA, 1(1), pp. 121-130.

[5] Kurniawan T.A., 2018. Pemodelan Use Case (UML): Evaluasi terhadap Beberapa Kesalahan dalam Praktik. Jurnal Teknologi Informasi dan Ilmu Komputer (JTIIK), 5(1), pp. 77-86.

[6] Nuris, M., 2015. White Box Testing pada Sistem Penilaian Pembelajaran. S. Kom. Malang: Universitas Islam Negeri Maulana Malik Ibrahim.

[7] Rosa, A.S. \& Shalahuddin, M., 2014. Rekayasa Perangkat Lunak Terstruktur dan Berorientasi Objek. Bandung: Informatika.

[8] Rothman, D., 2018. Artificial Intelligence By Example. 1st ed. Birmingham: Packt Publishing Ltd.

[9] Widiastuti I., dan Ayuninghemi R., 2016. Struktur Bayesian Network untuk Penentuan Class Karakteristik Siswa pada Sistem Tutor Cerdas. Seminar Nasional Hasil Penelitian dan Pengabdian Masyarakat 2016. Indonesia: Jember.

[10] Zuhri, A.S., 2018. Pengertian Servis (Perbaikan). [Online]. Tersedia http://aguszuhri26.blogspot.com/2014/11/pengertian-servisperbaikan.html/ [Accessed 10 Desember 2018. 